\title{
Subtle Psychological Violence and Couple Satisfaction among University Students
}

\author{
Aurelio Lascorz, Santiago Yubero, Elisa Larrañaga \\ Faculty of Social Work, University of Castilla, La Mancha, Spain \\ Email: aurelio.lascorz@uclm.es
}

How to cite this paper: Lascorz, A., Yubero, S., \& Larrañaga, E. (2020). Subtle Psychological Violence and Couple Satisfaction among University Students. Open Journal of Social Sciences, 8, 364-382. https://doi.org/10.4236/jss.2020.83033

Received: February 19, 2020

Accepted: March 22, 2020

Published: March 25, 2020

Copyright $\odot 2020$ by author(s) and Scientific Research Publishing Inc. This work is licensed under the Creative Commons Attribution International License (CC BY 4.0).

http://creativecommons.org/licenses/by/4.0/ (c) (i) Open Access

\begin{abstract}
Psychological aggressions are difficult to detect. For instance, different forms of micro male behaviours normally are so subtle that they go unnoticed. According to Intimate Partner Violence perspective, partner violence is bidirectional. Moreover, some authors have reported that partner violence is associated with low levels of satisfaction with the relationship. The objective of this study is cognisance of the incidence of subtle psychological abuse among couples of university students through micro male behaviours and to analyse how it is perceived, taking the sex and the role played into account (perpetrator, victim or both) and the differences depending on the strategies of psychological violence used. University students $(\mathrm{N}=1156)$ from 28 universities from all over Spain, throughout an academic course, participated in this crosssectional non-experimental study. In order to identify subtle psychological violence, the Questionnaire on Micro Male Conducts of Ferrer et al. (2008) was adapted to a self-report on behaviours used towards the partner (perpetration) and received from him/her (victimisation). Behaviours are grouped into five strategies. We have verified that the couples of young university students report high levels of involvement in micro male behaviours and confirm that aggressions are bidirectional. As far as satisfaction with the partner is concerned, the strategies of psychological violence of confinement to a traditional role and generating insecurity go unnoticed among men. An important difference is found, as women definitely are sensitive towards victimisation of insecurity by their partners. There is a common pattern in terms of strategies of invading spaces and underestimating; in both cases, they have an important impact on satisfaction with the partner and reduce the level thereof. These findings suggest that victims do not properly value the information received. In order to reduce psychological violence among couples, it is important that young people identify abusive behaviours and the level of violence they may be facing.
\end{abstract}




\section{Keywords}

Subtle Violence, Intimate Partner Violence, Couple Satisfaction

\section{Introduction}

It has repeatedly been proved that psychological violence can be just as harmful as physical abuse (Echeburúa \& Corral, 1998; O’Leary, 1999; Soler, Barreto, \& González, 2005). The results obtained by Buesa \& Calvete (2011) confirm that psychological abuse can have a very negative impact on the mental health and well-being of victims. Some authors (Cáceres, 2004; Cáceres \& Cáceres, 2006; Shortt, Capaldi, Kim, \& Laurent, 2010) have reported that partner violence is associated with low levels of satisfaction with the relationship.

Research in several countries on partner violence shows that violence is just as frequent or even more frequent among young couples than among adult couples (González, Muñoz, \& Graña, 2003; Jackson, Cram, \& Seymour, 2000). Much data support that violence usually starts in dating relationships, when aggression is part of partner relationships (Billingham, Bland, \& Leary, 1999; Muñoz-Rivas, Graña, O’Leary, \& González, 2007; O’Keefe, 1997; O’Leary, 1999). The proportion of young people who admit to practice violence against their partners is somewhere between 10\% and 50\% (González \& Santana, 2001; Hird, 2000; Jackson et al., 2000; Katz, Carino, \& Milton, 2002; Muñoz-Rivas, Andreu, Graña, O’Leary, \& González, 2007; Murphy \& Hoover, 2001; Swart, Garth, \& Ricardo, 2002). Although there are fewer studies on psychological violence among young people compared to physical or sexual violence, it has a higher incidence than physical violence (American College Health Association, 2007; Corral \& Calvete, 2006; Forke et al., 2008; Vázquez et al., 2010). The results obtained from the study conducted by Muñoz-Rivas et al. (2007) show that $30 \%$ of the students of either sex admitted that they had insulted their partner.

According to some studies, partner violence is bidirectional, that is to say, both genders can perpetrate and suffer violent behaviours simultaneously (Archer, 2000; Graña \& Cuenca, 2014). As far as psychological violence is concerned, more than $50 \%$ of Spanish youngsters report that it is common among couples (González \& Santana, 2001; Muñoz-Rivas, Graña, O’Leary, \& González, 2007). García-Carpintero, Rodríguez-Santero, \& Porcel (2017) have verified that psycho-emotional aggressions are common practice in partner relationships among university students of box genders.

Young people tend to identify violence with physical aggressions exclusively (Foshee et al., 1998), whose effects can be easily observed (O'Leary, 1999), while psychological aggressions are more difficult to detect (Cortés et al., 2014; Sackett \& Saunders, 1999). For instance, different forms of micro male behaviours are seen as "microabuses", as they are normally so subtle that they go unnoticed (Ferrer et al., 2008). Nevertheless, this concept is not the same depending on the 
point of view of the perpetrator or the victim; when violence is used by an individual, these behaviours can be seen as something normal, but when such behaviours are suffered by him/her, its perception changes and are seen as something unpleasant (García-Carpintero et al., 2017). Another underlying problem is the fact that they become normal in partner relationships as a strategy to resolve conflicts among young couples and become a rather usual element in their relationships (Sebastián, Ortiz, \& Gil, 2010).

According to Buesa \& Calvete (2011), the most subtle psychological abuse is a field that requires further knowledge, as its own nature has led to minimise its importance. The consequences of subtle psychological abuse are not known in depth (Buesa \& Calvete, 2011) and whether its impact is similar to man or women either.

I view of these facts, it is relevant to analyse psychological abuse from a broader perspective. It is necessary to overcome the trend to limit the measurement of psychological abuse to verbal acts. In this sense, we believe it would be interesting to analyse subtle psychological abuse from a broader perspective and to analyse how its consequences are perceived among partner relationships and to analyse whether it has a negative impact both on victims and perpetrators thereof.

The objective of this study is to take cognisance of the incidence of subtle psychological abuse among couples of university students through micro male behaviours and to analyse how it is perceived among young men and women, taking the role played into account (perpetrator, victim or both) and the differences depending on the strategies of psychological violence used.

\section{Methodology}

\subsection{Participants}

1156 university students from 28 universities from all over Spain, who reported being in a couple relationship at the moment of completing the questionnaire were selected for this study. 85.7\% are women (991), 14.3\% are men (165), aged 22.22 years on average ( $\mathrm{SD}=5.49) .27 .7 \%$ live together occasionally, $17.1 \%$ live together normally and more than half $(55.2 \%)$ do not live together.

\subsection{Instruments}

In order to identify subtle psychological violence, the Questionnaire on Micro Male Conducts of Ferrer et al. (2008) was adapted to a self-report on behaviours used towards the partner (violence perpetration) and received from him/her (violence victimisation). In total, this self-report includes 24 conducts (see Table 2, item $n^{\circ} .11$ referring to maternity was eliminated), using a Likert-type answer scale with four answers: 0-Never, 1-Seldom, 2-Sometimes and 3-Often. Ferrer et al. (2008) report five micromachist strategies that group behaviours according to their purpose: Invading physical or symbolic spaces, creating insecurity, confining to a traditional role, exercising control or underestimating. 
Satisfaction with the partner was evaluated using a direct item, "How satisfied are you with your current partner?", the answer scale ranges from 0 to 10.

\subsection{Procedure}

The data collection procedure met the requirements set forth in the Code of Good Scientific Practices approved by the Spanish Higher Council for Scientific Research (CSIC, as per its Spanish acronym). The sample is incidental. The questionnaires were distributed in the classrooms at the university with the collaboration of teachers throughout an academic course. All the students participated voluntarily and anonymousness was guaranteed.

\subsection{Statistical Analyses}

The percentage of participation in micro male conducts was calculated in the first place, segmented by men and women, and a comparison was made using the chi-square test. The means of satisfaction with the partner depending on gender and the strategy of psychological violence used were then compared. Based on the scores obtained in the questionnaires, the results are classified according to the role played in each of the sexes regarding behaviours of subtle psychological violence: He/she not involved, Perpetrator, Victim and Mutual.

The size of the impact on differences, which became significant with $\mathrm{d}$ and $\eta^{2}$, respectively, was calculated. In last place, the regression analyses for victimisation and perpetration were performed. The analyses were performed using the SPSS Statistics 24 software.

\section{Results}

The characteristics of intimate partner relationships are shown in Table 1. Of 1156 university students who reported being in a couple relationship, 85.7\% were women (991), 14.3\% were men (165), aged 22.22 years on average $(\mathrm{SD}=$

Table 1. Characteristics of intimate partner relationships.

\begin{tabular}{cccc}
\hline & Women & Men & $\mathrm{t} / \chi^{2}(p)$ \\
\hline Mean of number of partners & 2.10 & 2.81 & $-4.05(.000)$ \\
Mean duration of relations (in months) & 38.60 & 28.10 & $4.25(.000)$ \\
Daily cohabitation & & & \\
Live together occasionally & $17.8 \%$ & $11.8 \%$ & $1.83(.608)$ \\
Live together continuously & $10.8 \%$ & $9.2 \%$ & \\
Never have lived together & $35.6 \%$ & $23.8 \%$ & $55.2 \%$ \\
No information & $35.8 \%$ & & \\
Current time relationship & & $58.1 \%$ & \\
More than 3 years & $43.1 \%$ & $19.3 \%$ & \\
Between 18 and 36 months & $27.6 \%$ & $22.6 \%$ & \\
Less than 18 months & $29.3 \%$ & &
\end{tabular}


5.49). $27.7 \%$ lived together occasionally, $17.1 \%$ lived together normally and more than half $(55.2 \%)$ do not live together.

$80 \%$ of women and $70 \%$ of man are involved in behaviours of subtle psychological violence within their couples. $71.8 \%$ are aggressors and $68 \%$ are victims. Women use more violence against their partners (73.3\% of women, $69 \%$ of men, $\left.\chi^{2}=11.91, p<.001\right)$, but both genders are equally victimised $(69 \%$ of women, $61.8 \%$ of men, $\left.\chi^{2}=3.37, p=.06\right)$. If involvement roles are analysed, we can confirm that women are more frequently involved in aggressions, $10.3 \%$ are perpetrators and $63.4 \%$ in common, while the proportion of men who are perpetrators amounts to $60.6 \%$, and in $52.7 \%$ of cases it is mutual, $\chi^{2}=12.07, p<.01$.

Table 2 shows the distribution of percentages of participants in each one of the micro male conducts, analysed depending on gender.

As can be seen in Table 2, women are more frequently involved in aggressions including micro male conducts. There is no significant difference between men and women in terms of role strategies or control strategies, although men report neglecting domestic responsibilities to a greater extent and women report being neglected by their partners compared to these responsibilities more often. As far as control strategies are concerned, women report greater mutual control of the schedules.

Invading spaces is one of the strategies most frequently used, by women to a greater extent. Not expressing their feelings is the only behaviours that seem to be more frequently used by men $(12.3 \%)$, which coincide with a greater victimisation reported by women (14.6\%); although $10.5 \%$ women also report that this strategy is mutual and $10.4 \%$ of men report victimisation. Both genders report greater perpetration among women and greater victimisation among men in terms of reading e-mail messages and listening to telephone conversations, as well as getting what they want from their partner due to fatigue. Data reveal that women use strategies such as not listening, interrupting or manipulating the message more often, which amount almost to $16 \%$ when this strategy is mutual. Men report being more victimised by the threat of leaving the relationship $(6.4 \%)$ but this figure does not match what women report (3.6\% of perpetration of this strategy).

Although most of them deny its use (64.1\% of women, $72.1 \%$ of men), making decisions unilaterally is the strategy most frequently used in terms of underestimating the partner. The fact that women use this strategy more often $(7.3 \%$, compared to $3.6 \%$ of men) coincides with the fact that men are more victimised in this sense ( $8.7 \%$, compared to $6 \%$ of women). As far as the strategies to create insecurity are concerned, the difference lies in getting angry without knowing the reason (10.1\% perpetrated by women, $9.0 \%$ of victims are men) and using the glance or tone of voice to frighten the partner (women: $6.4 \%$ are perpetrators by women, $6.4 \%$ mutual; men: $4.2 \%$ are victims, $1.4 \%$ are perpetrators, $3.6 \%$ mutual).

University students report great satisfaction with their partners $(M=8.56 ; S D$ 
Table 2. Comparison of profiles in terms of micro male conducts within the couples, in percentage.

\begin{tabular}{|c|c|c|c|c|c|c|c|c|c|}
\hline & \multicolumn{4}{|c|}{ Women } & \multicolumn{4}{|c|}{ Men } & \multirow[b]{2}{*}{$x^{2}$} \\
\hline & 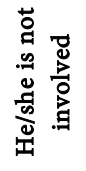 & 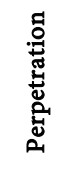 & 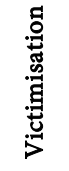 & $\stackrel{\Xi}{\Xi}^{J}$ & 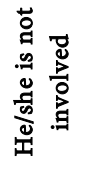 & 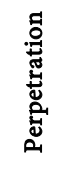 & 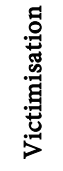 & 䙃 & \\
\hline INVADING SPACES & 35.8 & 11.0 & 9.1 & 44.1 & 49.1 & 9.7 & 13.3 & 27.9 & $18.37^{* * *}$ \\
\hline $\begin{array}{l}\text { 6) Getting what you want from your partner due to fatigue, getting it due to his/her } \\
\text { burnout }\end{array}$ & 75.5 & 10.1 & 6.1 & 8.4 & 78.7 & 7.0 & 9.0 & 5.3 & $10.31^{* *}$ \\
\hline 10) Monopolising the use of common spaces or elements & 84.1 & 5.0 & 5.9 & 5.0 & 88.0 & 5.0 & 4.5 & 2.5 & 5.42 \\
\hline 15) Interrupting, not listening, not answering, manipulating the message & 68.3 & 8.2 & 7.8 & 15.8 & 73.1 & 6.7 & 10.4 & 9.8 & $11.19^{* *}$ \\
\hline $\begin{array}{l}\text { 17) Reading messages or e-mails without permission or listening to telephone } \\
\text { conversations }\end{array}$ & 77.9 & 10.6 & 5.5 & 5.9 & 81.2 & 3.9 & 10.9 & 3.9 & $29.02^{* * *}$ \\
\hline 18) Not expressing his/her feelings, often shutting down emotionally & 65.4 & 9.5 & 14.6 & 10.5 & 69.2 & 12.3 & 10.4 & 8.1 & $8.21^{*}$ \\
\hline 19) Making excuses to justify himself/herself & 73.6 & 8.0 & 10.0 & 8.4 & 75.1 & 9.2 & 7.0 & 8.7 & 3.37 \\
\hline 20) Cheating, lying, not honouring what has been agreed & 87.7 & 2.3 & 7.8 & 2.1 & 85.7 & 3.6 & 8.4 & 2.2 & 2.15 \\
\hline 22) Calling fidelity into question & 84.6 & 6.2 & 5.1 & 4.1 & 80.1 & 7.8 & 8.7 & 3.4 & 8.78 \\
\hline 23) Threatening to leave the relationship and have an affair with someone else & 92.2 & 3.6 & 2.9 & 1.3 & 89.4 & 3.1 & 6.4 & 1.1 & $10.42^{* *}$ \\
\hline 24) Making his/her partner feel sorry for him/her & 87.9 & 2.6 & 8.0 & 1.4 & 84.3 & 3.9 & 9.0 & 2.8 & 5.66 \\
\hline CREATING INSECURITY & 59.6 & 15.6 & 5.7 & 19.1 & 67.3 & 6.1 & 9.1 & 17.6 & $13.35^{* *}$ \\
\hline 1) Frightening the partner through his/her tone of voice, glance or gestures & 83.6 & 6.4 & 3.6 & 6.4 & 90.8 & 1.4 & 4.2 & 3.6 & $19.03^{* * *}$ \\
\hline 4) Not respecting his/her partner's opinions and rights & 82.5 & 5.9 & 5.5 & 6.1 & 83.5 & 3.9 & 7.6 & 5.0 & 4.81 \\
\hline 5) Not respecting his/her partner's feelings & 86.9 & 2.5 & 5.9 & 4.6 & 86.6 & 2.2 & 8.1 & 3.1 & 3.78 \\
\hline 13) Creating insecurity or feelings of guilt by insinuating or manipulating emotions & 82.0 & 5.6 & 7.6 & 4.8 & 84.6 & 2.5 & 8.4 & 4.5 & 6.08 \\
\hline $\begin{array}{l}\text { 14) Getting angry or making surly or aggressive comments unexpectedly without } \\
\text { knowing the reason }\end{array}$ & 78.9 & 10.1 & 6.4 & 4.7 & 84.0 & 3.4 & 9.0 & 3.6 & $19.22^{* * *}$ \\
\hline CONFINEMENT TO A TRADITIONAL ROLE & 65.2 & 10.3 & 11.8 & 12.7 & 60.1 & 12.7 & 5.5 & 12.7 & 6.35 \\
\hline 12) Discouraging his/her partner, making studying or working harder for him/her & 95.2 & 0.8 & 3.6 & 0.4 & 92.4 & 1.7 & 4.8 & 1.1 & 6.17 \\
\hline 16) Seeing his/her partner as a child who needs to be cared for or protected & 73.0 & 14.8 & 5.4 & 6.9 & 78.7 & 10.6 & 4.8 & 5.9 & 5.48 \\
\hline 21) Neglecting his/her domestic responsibilities & 81.7 & 3.3 & 12.2 & 2.8 & 88.8 & 5.3 & 3.9 & 2.0 & $24.34^{* * *}$ \\
\hline EXERCISING CONTROL & 72.6 & 6.6 & 5.8 & 15.1 & 81.2 & 3.6 & 3.6 & 11.5 & 5.83 \\
\hline 7) Controlling his/her partner's money or expenses & 91.4 & 4.0 & 2.2 & 2.3 & 92.2 & 3.4 & 2.5 & 2.0 & 0.73 \\
\hline 8) Controlling his/her partner's schedules, meetings or activities & 80.0 & 3.0 & 6.3 & 10.7 & 86.0 & 3.1 & 5.0 & 5.9 & $8,97^{*}$ \\
\hline $\begin{array}{l}\text { 9) Complaining at his/her partner so that he/she goes out or relate to his/her family } \\
\text { and friends }\end{array}$ & 88.3 & 2.2 & 7.0 & 2.5 & 90.8 & 1.7 & 5.9 & 1.7 & 1.90 \\
\hline UNDERESTIMATING & 64.1 & 9.1 & 6.8 & 20.1 & 72.1 & 3.0 & 7.3 & 17.6 & $8,21^{*}$ \\
\hline 2) Making important decisions without taking his/her partner's opinion into account & 71.9 & 7.3 & 6.0 & 14.8 & 70.3 & 3.6 & 8.7 & 17.4 & $10.41^{* *}$ \\
\hline 3) Change decisions made by his/her partner & 85.2 & 5.4 & 4.5 & 5.0 & 87.7 & 1.7 & 6.4 & 4.2 & $11.17^{* *}$ \\
\hline 25) Downplaying the importance of duties or activities performed by his/her partner & 85.9 & 3.4 & 6.9 & 3.9 & 86.8 & 3.4 & 6.7 & 3.1 & 0.50 \\
\hline
\end{tabular}

Note: ${ }^{*} p<.05,{ }^{* *} p<.01,{ }^{* *} p<.001$. 
$=1.93$ ). $25.8 \%$ are totally satisfied with their relationship, scoring 10 out of 10 (it should be noted that the scale used ranges from 0 to 10). $57.4 \%$ score between 8 and 9 , and only 7 students (2\%) scored below 5 .

As far as involvement in subtle psychological behaviours is concerned, there are no significant differences in terms of perception of satisfaction with the partner between men and women $(M$ woman $=8.32, M$ man $=8.42, t=-.59, p$ $=.557)$, or in terms of perpetrators $(M$ woman $=8.37, M$ man $=8.55, t=-1.06, p$ $=.289)$. Nevertheless, there are significant differences in each gender depending on the different levels of involvement in such behaviours (Women: Mis not involved $=8.97$, Mvictim $=8.32, t=6.56, p<.001$; Men: Mis not involved $=9.02$, $M$ victim $=8.42, t=2.93, p<.05)$. These data show that man do not see perpetration negatively with respect to their satisfaction with their partners, but the answer from women is very different (Women: Mis not involved $=8.94$, Mperpetrator $=8.37, t=5.44, p<.001$; Men: Mis not involved $=8.81, M$ perpetrator $=$ $8.55, t=1.24, p=.216)$.

If we take the correlation between perpetration and victimisation into account (women, $r=.610, p<.000$; men, $r=.667, p<.000$ ) and the high proportion of these behaviours that are mutual is reported, it is necessary to analyse satisfaction depending on the roles played by each one in the intervention, including such mutual nature in these behaviours. Table 3 shows that there are no significant differences between men and women in any of the intervention roles. On the contrary, there are differences in each one of the genders depending on the role played, although these differences have a small impact.

No involvement, perpetration and victimisation are groped within women. Those women who report mutual behaviours are clearly distinguishable of the other three women (is not involved, $p<.001$, perpetrator, $p<.001$, victim, $p$ $<.01$ ), and report a lower level of satisfaction with their partners. No involvement and perpetration are grouped within men, as well as victimisation and mutual behaviours, which are significantly different from no involvement (victim, $p<.05$, mutual, $p<.05)$.

If we consider that men and women react differently to psychological violence and the differences in micro male conduct evidenced by each one, we have

Table 3. Satisfaction with the relationship depending on the intervention role.

\begin{tabular}{ccccc}
\hline & Woman & Man & $\boldsymbol{t}$ & $\boldsymbol{p}$ \\
\hline He/she is not involved & 8.98 & 9.00 & -.16 & .872 \\
Perpetrator & 8.97 & 9.08 & -.41 & .682 \\
Victim & 8.82 & 8.14 & 1.81 & .075 \\
Mutual & 8.28 & 8.47 & -1.03 & .305 \\
$F$ & 16.84 & 3.14 & & \\
$p$ & .000 & .027 & & \\
$\eta^{2}$ & .05 & .05 & & \\
\hline
\end{tabular}


analysed the level of satisfaction with their partners depending on the intervention roles for each one of the strategies of violence. These data are shown in Table 4.

There are significant differences in all the strategies of psychological violence among women. Regarding the strategies of traditional role and controlling the significant other, the impact is small. As far as the strategies of controlling satisfaction with the partner is similar in the roles of no involvement, perpetration and mutual behaviours; although the lowest level of satisfaction corresponds to the role of victim, which is clearly distinguishable from the other roles (no involvement, $p<.001$, perpetration, $p<.001$, mutual, $p<.001$ ). The same difference is found in the control strategy of men (no involvement, $p<.001$, perpetration, $p<.05$, mutual, $p<.001)$. Those victims who are controlled by their partners report a lower level of satisfaction with their relationship $(M$ women $=7.36$, Mmen = 6.80)

The satisfaction of victims and those who are involved in mutual behaviours are similar both among men and women. Women are more sensitive towards violent strategies of insecurity than men. There are no significant differences among men in terms of satisfaction with their partners in terms of involvement roles of this strategy. There are no significant differences either among men in terms of strategies of traditional role.

Men do not perceive perpetration in any strategy. Women associate perpetration to a significantly lower level of satisfaction with their partners rather than to non-involvement in the strategy of traditional role $(p<.001)$ or underestimating $(p<.05)$.

In the strategies of invading spaces, which are the most frequent, victimisation

Table 4. Differences in satisfaction depending on micro male strategies and gender.

\begin{tabular}{ccccccc}
\hline & $\begin{array}{c}\text { He/she is } \\
\text { not involved }\end{array}$ & Perpetrator & Victim & Mutual & $F$ & $\eta^{2}$ \\
\hline Woman & & & & & & \\
Invading spaces & 8.92 & 8.88 & 8.37 & 8.17 & $21.65^{* * *}$ & .066 \\
Insecurity & 8.79 & 8.67 & 7.69 & 7.91 & $26.77^{* * *}$ & .076 \\
Traditional role & 8.79 & 8.14 & 8.08 & 8.01 & $19.76^{* * *}$ & .052 \\
Control & 8.66 & 8.49 & 7.36 & 8.42 & $15.43^{* * *}$ & .042 \\
Underestimation & 8.80 & 8.44 & 7.75 & 8.00 & $24.37^{* * *}$ & .061 \\
Man & & & & & & \\
Invading spaces & 8.86 & 9.00 & 8.62 & 8.18 & $3,10^{*}$ & .062 \\
Insecurity & 8.69 & 9.20 & 8.64 & 8.33 & 1.16 & \\
Traditional role & 8.76 & 8.89 & 8.00 & 8.21 & 2.08 & \\
Control & 8.72 & 8.40 & 6.80 & 8.83 & $4.13^{* *}$ & .076 \\
Underestimation & 8.92 & 8.25 & 7.82 & 7.96 & $6.68^{* * *}$ & .118 \\
\hline
\end{tabular}

Note: ${ }^{\star} p<.05,{ }^{* *} p<.01,{ }^{* * *} p<.001$. 
is only perceived by women ( $p<.001$ compared to no involvement, $p<.01$ compared to perpetration).

Table 5 shows the results of linear regression regarding satisfaction for victimisation and perpetration of strategies of psychological violence, segmented by men and women. $25 \%$ of satisfaction with the relationship with the partner among women seems to depend on the victimisation of subtle psychological violence; men are affected by this victimisation to a lesser extent, only $18 \%$. Perpetration has a more similar impact on women and men, $18 \%$ and $15 \%$, respectively. In fact, there are differences in victimisation of the strategies of insecurity, while these are not very significant among men. The perpetration of strategies of control increases satisfaction with the relationship with their partners among women, while it has no impact among men. Both genders are sensitive towards the influence of victimisation and perpetration of the strategies of invading spaces-women to a greater extent-while the results regarding strategies of underestimating among men are more significant.

\section{Discussion}

According to the objectives of this study, we focus on analysing the perception of psychological violence with regard to satisfaction. To that end, we have previously analysed the presence of micro male behaviours, but with the understanding that

Table 5. Regression analyses for victimisation and perpetrations by gender

\begin{tabular}{|c|c|c|c|c|}
\hline & \multicolumn{2}{|c|}{ Woman } & \multicolumn{2}{|c|}{ Man } \\
\hline & $\beta$ & $\mathbf{t}$ & $\beta$ & $\mathbf{t}$ \\
\hline \multicolumn{5}{|l|}{ Victimisation } \\
\hline Invading spaces & -.34 & $-8.19^{* * *}$ & -.25 & $-2.19^{*}$ \\
\hline Insecurity & -.16 & $-4.05^{\star \star \star}$ & -.05 & -.51 \\
\hline Traditional role & -.01 & -.22 & .02 & .18 \\
\hline Control & .05 & 1.49 & .09 & .98 \\
\hline Underestimation & -.09 & $-2.46^{*}$ & -.27 & $-3.11^{* * *}$ \\
\hline$R^{2}$ & \multicolumn{2}{|c|}{.25} & \multicolumn{2}{|c|}{.18} \\
\hline$F$ & \multicolumn{2}{|c|}{$86.60^{* * *}$} & \multicolumn{2}{|c|}{$7.01^{* * *}$} \\
\hline \multicolumn{5}{|l|}{ Perpetration } \\
\hline Invading spaces & -.25 & $-6.19^{* \star *}$ & -.25 & $-2.49^{\star}$ \\
\hline Insecurity & -.07 & -1.79 & .01 & .05 \\
\hline Traditional role & -.12 & -1.54 & .09 & .99 \\
\hline Control & .08 & $2.55^{* *}$ & .11 & 1.22 \\
\hline Underestimation & -.08 & $-2.25^{\star}$ & -.34 & $-4.02^{\star * *}$ \\
\hline$R^{2}$ & \multicolumn{2}{|c|}{.15} & \multicolumn{2}{|c|}{.18} \\
\hline$F$ & \multicolumn{2}{|c|}{$34.92^{* * *}$} & \multicolumn{2}{|c|}{$6.95^{* * *}$} \\
\hline
\end{tabular}

Note. ${ }^{*} p<.05,{ }^{* *} p<.01,{ }^{* * *} p<.001$. 
this behaviour can be mutual.

As far as involvement in micro male behaviours is concerned, our results show there is a higher level of involvement in psychological violence than reported in previous studies, eight out of ten women and seven out of ten men, although we should take into account that the range of behaviours analysed is wider. Upon analysing micro male behaviours jointly, $62 \%$ of the couples report mutual behaviours, which confirm this bidirectional nature reported in previous studies (Graña \& Cuenca, 2014; González \& Santana, 2001; Muñoz-Rivas et al., 2007). Partly as in previous studies (Corral \& Calvete, 2006; Muñoz-Rivas et al., 2007), involvement of women in psychological violence was slightly higher compared to men; nevertheless, there was not any significant difference in terms of victimisation between genders among our subjects of study.

If we analyse involvement in different strategies, invading spaces seems to be a common strategy in partner relationships, as more than half of the university students are involved therein (64\% of women and 51\% of men). A higher percentage of women, $44 \%$, report mutual behaviours. The results obtained show the existence of a common pattern among man and women that consist of not listening, on not answering and on manipulating the messages. Men do not convey their emotions and it seems that women do not do it either consequently. The results show that women invade privacy of telephone conversations and private messages to a greater extent, and get what they want from their partners due to fatigue.

As reported in other previous studies (Corral, 2009), the highest percentage of strategies of psychological violence correspond to no involvement. Although Muñoz-Rivas et al. (2007) stated that control tactics are the most common ones, our results incline in the opposite direction; controlling the partner is the least reported by the university students who participated in this study, and no significant differences were found between men and women in terms of involvement.

As far as the perception of psychological violence is concerned, university students are satisfied with their partner relationship. Even the mean of those couples who are involved in behaviours of psychological behaviour amount above 7 points out of 10 . As stated in previous research, it seems that men and women do not see psychological violence as an aggression (Cortés et al., 2014; Sackett \& Saunders, 1999), and do not see micro male behaviours as violence (Ferrer et al., 2008). In short, both genders normalise behaviours of psychological violence and incorporate them into the dynamics of their partner relationship (Sebastián et al., 2010).

Nevertheless, some statistically significant differences are found in terms of satisfaction depending on involvement. This same phenomenon is found among men, according to García-Carpintero et al. (2017): they do not perceive aggression but they are sensitive towards victimisation. Contrarily, women seem to see psychological violence both as an aggression and victimisation. The analysis of satisfaction with the partner depending on the involvement roles helps us to de- 
fine these results and the differential response of man and women to psychological violence within the couple. In both cases, men and women who report perpetration only do not seem to see their behaviour as an aggression and have the same level of satisfaction with their partner as those students who are not involved in such behaviours. Women who are victims are divided into two clearly different groups: a few of them (5.7\%) only report being a victim and do not seem to recognise victimisation negatively as an aggression; this way, they have the same level of satisfaction as those women who perpetrate aggressions and those who are not involved therein. The response of most women who are victims of psychological violence (63.4\%) consists of perpetrating on attacking their partners. A significantly lower level of satisfaction is found in this mutual role, compared to the other roles. All men seem to perceive victimisation. Those men who report being victims $(9.1 \%)$ have a lower level of satisfaction than those men who are perpetrators or who are not involved in these behaviours; therefore, they have the lowest level of satisfaction. In most cases, their response (52.7\%) also consists of attacking their partners. From a feminist point of view, McNulty \& Russell (2010) reported that the tendency of women to have violent behaviours when they are rejected or criticised by their partners is a predictor of a higher level of satisfaction than when there is no response whatsoever. This phenomenon is not reported among women or among men either. Those women who engage in violent mutual strategies report a lower level of satisfaction. Those men who engage in violent mutual strategies have the same level of satisfaction than those who are victims only.

These results make us conclude that mutual involvement is a response to an aggression perpetrated by the partner, both among men and women. Nevertheless, attacking the partner in response to an aggression is not a good solution for any of them. Notwithstanding the foregoing, we cannot determine the direction of violence on the basis of such data. We cannot know is psychological violence is triggered by the man or the woman. It would be necessary to conduct longitudinal studies that let us know how these patterns of subtle psychological partner violence are started.

If a detailed analysis of satisfaction with the partner is conducted, according to the strategies of psychological violence studied, the results obtained show that the strategies of role and the strategies to generate insecurity go unnoticed. Strategies and control strategies are not very significant among women. In fact, both men and women take a positive view of controlling their partner and vice-versa. It is possible that control over the partner is exercised by agreement. Some authors state that young people tend to justify and see controlling behaviours as something normal due to the idealisation of love (Ferrer \& Bosch, 2013). In fact, those men and women who are victims of controlling behaviours have the lowest levels of satisfaction with their partner relationship. The strategies of invading spaces and underestimating are a common pattern for both genders; it seems that both men and women perpetrate aggressions as a conse- 
quence of being attacked. But there is also a differential pattern by which women are more sensitive towards insecurity. Otherwise, it is found that women who underestimate their partners are distinguished from women who do not participate; we can see this fact as a deliberate response to aggression by the man, probably in response to an aggression perpetrated by him using some of the other strategies.

The results of this regression confirm the data already summarised. Women are more sensitive to victimisation by means of psychological violence, which can even explain that $25 \%$ are not satisfied with their partner relationships. There is previous evidence that physical violence has greater impact on university who are university students than on their male peers (Muñoz-Rivas et al., 2007). We can thus state that this phenomenon also affects psychological violence. Psychological violence also has an impact on satisfaction with the partner but to a lesser extent than other types of violence. These results confirm that psychological violence is used by both genders, but it is normally used in response to an aggression.

Both genders are less satisfied with partner relationships when facing psychological violence in terms of invading spaces and underestimating. As far as aggression in concerned, the lowest results correspond to invading spaces among women and to underestimating among men. As far as women are concerned, controlling their partners increases satisfaction.

According to these results, we can state that psychological violence, under subtle forms, is a behaviour that falls within everyday life of young people's relationship and it is often hard for them to identify it as a form of abusive relationship. Previous research has already indicated that despite the presence of subtle violent behaviours within the couple, relationships are usually stable (Follingstad, Bradley, Laughlin, \& Burke, 2002). According to Cortés et al. (2014), the most worrying thing is that young people do not see psychological violence as an abusive behaviour by their partners and even see it as a token of love. In order for someone to break up a violent relationship, he/she must first realise what is going on and what is the real consequences of keeping such relationship (González \& Santana, 2001). Nevertheless, if violence starts in dating relationships, it seems that victims do not properly value the information received on these behaviours. In order to eliminate or reduce psychological violence among couples, it is important that young people identify abusive behaviours and the level of violence they may be facing. Some studies have shown that it is difficult to identify situations of violence due to inappropriate, incomplete and highly stereotyped beliefs by young people (Bleakley, Hennessy, Fishbean, Coles, \& Jordan, 2009).

This research also has certain limitations. It is a cross-sectional study and as such it does not allow to evaluate if the experiences of psychological violence were prior to the reduction of satisfaction in couple relationships or if it was prior and influenced subsequent micromachist behaviors. According to previous 
research, the higher the level of satisfaction with the partner relationship is, the lower the probability of being a victim of gender-based violence is (Stith, Green, Smith, \& Ward, 2008).

Moreover, a stable link between verbal and psychological abuse and episodes of physical violence is found (Murphy \& O'Leary, 1989; O'Leary \& Slep, 2003; White, Merrill, \& Koss, 2001). We have only analysed psychological violence and it is possible that mild physical violence is simultaneously being inflicted in some cases. It would be interesting to expand research including physical violence too.

\section{Conclusion}

In this study, we have verified that the couples of young university students report high levels of involvement in micro male behaviours. A higher percentage of women than men reported being engaged in behaviours of subtle psychological violence against their partners. This research also confirms that aggressions are bidirectional, involving a high percentage of mutual violence within the couple. It is important to note that this study focused on mild psychological aggressions within the couple and the results and conclusions thereof cannot be applied to other types of more serious aggressions.

Not respecting the physical and psychological spaces seems to be the most frequent strategy among both genders. But both genders also underestimate and generate insecurity in their partners, engaging in controlling behaviours of the schedules and activities.

There is a lack of perception of the perpetration of micro male behaviours. From a feminist point of view, it is understood that men have aggressive behaviours against women based on a patriarchal society resulting from male socialisation. Nevertheless, according to our study, men and women who are university students have a similar behaviour. Those women who act as perpetrators do not see their behaviour as an aggression either.

As far as satisfaction with the partner is concerned, the strategies of psychological violence of confinement to a traditional role and generating insecurity go unnoticed among men. An important difference is found in this sense, as women definitely are sensitive towards victimisation of insecurity by their partners. There is a common pattern in terms of strategies of invading spaces and underestimating; in both cases, they have an important impact on satisfaction with the partner and reduce the level thereof.

As a matter of fact, the tactic reported by students consists of striking back and attacks the partner in a similar way, but their level of satisfaction is lower. It is important to note that even in such circumstances of mutual behaviours and subtle psychological aggression, they are fairly satisfied with their relationships, although to a lesser extent than those couples who are not involved in micro male behaviours. The foregoing leads us to affirm that young people see micro male behaviours as something inherent to partner relationships.

They also seem to see controlling their partners as something normal and 
there are no differences compared to no involvement both in terms of perpetration and as a mutual behaviour. It even becomes a determining variable of the increase in satisfaction with the partner among women. Nevertheless, those men and women who are victims of controlling behaviours and do not strike back face the worst situation in terms of level of satisfaction with their partner relationships.

On analysing psychological violence globally, men are more sensitive towards satisfaction with their partners, so all the victims reported a lower level of satisfaction, while it was not a negative experience for a small proportion of women. It could also be due to a lack of recognition under the form of acceptance of romantic myths. Nevertheless, all the women who reported being victims with a lower level of satisfaction with their partners stroke back using psychological violence, therefore this behaviour becomes mutual. This fact can be explained as a break with the submissive role of women and their empowerment within the couple, which could be seen as greater gender equality. But it may also be due to an increase in other features that are not that positive. Anyway, it does not seem to be an appropriate strategy for either gender.

With the support of Social Work, it is essential to ensure young people understand that violence is not a way to solve conflicts, as violence can never be stopped with violence. It would be necessary to teach conflict-solving techniques based on empathy, communication and agreements to solve any conflicts arising in relationships with both members of the couples. Saying what we like and what we do not like is important, what is harmful or not, or what we expect and wish in our relationship.

Falling in love is an emotional response that implies the need for proximity, lust and passion, together with concern for the well-being of the significant other. In the first stages of falling in love, we are less rational and critical of the other person because the confidence area of our brain is activated. Nevertheless, it is essential that love maintaining both persons, without one person overriding the other person, maintaining their personal spaces; each one must seek his/her own happiness and develop his/her skills. Love must be as close as possible to freedom, it has to fill ourselves with energy and courage for our personal and common projects and drive the development of a strong identity and self-concept. It would be necessary to conduct educational activities that help young people to perform cognitive actions on what is abusive in partner relationships. Psychological violence cannot be inherent to human relationships and we must not allow young people to build their partner relationships on the acceptance of micro male behaviours, which have an impact on satisfactory partner relationships.

\section{Acknowledgements}

This research is part of RDI Project PSI2015-70822-R of the Ministry of Economy and Competitiveness of Spain, within the framework of the Retos programme. 


\section{Conflicts of Interest}

The authors declare no conflicts of interest regarding the publication of this paper.

\section{References}

American College Health Association (2007). American College Health Association National College Health Assessment Spring 2006 Reference Group Data Report (Abridged). Journal of American College Health, 55, 195-206. https://doi.org/10.3200/JACH.55.4.195-206

Archer, J. (2000). Sex Differences in Aggression between Heterosexual Partners: A Meta-Analytic Review. Psychological Bulletin, 126, 651-680. https://doi.org/10.1037/0033-2909.126.5.651

Billingham, R. E., Bland, R., \& Leary, A. (1999). Dating Violence at Three Time Periods: 1976, 1922, and 1996. Psychological Reports, 85, 574-578. https://doi.org/10.2466/PR0.85.6.574-578

Bleakley, A., Hennessy, M., Fishbean, M., Coles, H. C., \& Jordan, A. (2009). How Sources of Sexual Information Relate to Adolescents' Beliefs about Sex. American Journal of Health Behavior, 33, 37-48. https://doi.org/10.5993/AJHB.33.1.4

Buesa, S., \& Calvete, E. (2011). Adaptación de la escala de abuso psicológico sutil y manifiesto a las mujeres en muestra clínica y de la comunidad. [Adaptation of the Subtle and Overt Psychological Abuse of Women Scale in Clinical and Community Samples.] Anales de Psicología, 27, 774-782.

Cáceres, A., \& Cáceres, J. (2006). Violencia en relaciones íntimas en dos etapas evolutivas. [Violence in Intimate Relationships in Two Evolutionary Stages.] Intenational Journal of Clinical and Health Psychology, 6, 271-284.

Cáceres, J. (2004). Violencia física, psicológica y sexual en el ámbito de la pareja: Papel del contexto. [Physical, Psychological and Sexual Violence in the Sphere of the Couple: Role of Context.] Clínica y Salud, 15, 33-34.

Corral, S. (2009). Estudio de la violencia en el noviazgo en jóvenes universitarios/as: Cronicidad, severidad y mutualidad de las conductas violentas. [Study of Dating Violence in Young University Students: Chronicity, Severity and Mutuality of Violent Behaviors.] Psicopatología Clínica Legal y Forense, 9, 29-48.

Corral, S., \& Calvete, E. (2006). Evaluación de la violencia en las relaciones de pareja mediante las escalas de tácticas para conflictos: estructura factorial y diferencias de género en jóvenes. [Evaluation of Violence in Relationships through the Scales of Conflict Tactics: Factor Structure and Gender Differences in Young People.] Behavioral Psychology 14, 215-233.

Cortés, M. L., Bringas, C., Rodríguez-Franco, L., Flores, M., Ramiro-Sánchez, T., \& Rodríguez, F. J. (2014). Unperceived Dating Violence among Mexican Students. International Journal of Clinical and Health Psychology, 14, 39-47. https://doi.org/10.1016/S1697-2600(14)70035-3

Echeburúa, E., \& Corral, M. P. (1998). Manual de violencia familiar. [Family Violence Handbook.] Madrid: Siglo XXI.

Ferrer, V. A., Bosch, E., Navarro, C., Ramis, M. C., \& García, M. E. (2008). Los micromachismos o microviolencias en la relación de pareja: Una aproximación empírica. [Micromachisms or Micro Violence in the Couple: An Empirical Approximation.] Anales de Psicología, 24, 341-352.

Ferrer, V., \& Bosch, E. (2013). Del amor romántico a la violencia de género. Para una 
coeducación emocional en la agenda educativa. [From Romantic Love to Gender Violence. For an Emotional Coeducation in the Educational Agenda.] Profesorado, 17, 105-122.

Follingstad, D. R., Bradley, R. G., Laughlin, J. E., \& Burke, L. (2002). Risk Factors and Correlates of Dating Violence: The Relevance of Examining Frequency and Severity Levels in a College Sample. Violence and Victims, 14, 365-380. https://doi.org/10.1891/0886-6708.14.4.365

Forke, C. M., Myers, R. K., Catallozzi, M., \& Schwarz, D. F. (2008). Relationship Violence among Female and Male College Undergraduate Students. Archives of Pediatrics \& Adolescent Medicine, 162, 634-641. https://doi.org/10.1001/archpedi.162.7.634

Foshee, V. A., Bauman, K. E., Arriaga, X. B., Helms, R. W., Koch, G. G., \& Linder, G. F. (1998). An Evaluation of Safe Dates, an Adolescent Dating Violence Program. American Journal of Public Health, 88, 45-50. https://doi.org/10.2105/AJPH.88.1.45

García-Carpintero, M. A., Rodríguez-Santero, J., \& Porcel, A. M. (2017). Diseño y validación de la escala para la detección de violencia en el noviazgo en jóvenes de la Universidad de Sevilla. [Design and Validation of the Scale for the Detection of Violence in Courtship in Young People in the Sevilla University (Spain).] Gaceta Sanitaria, 32, 121-128. https://doi.org/10.1016/j.gaceta.2017.09.006

González, M. P., Muñoz, M., \& Graña, J. L. (2003). Violencia en las relaciones de pareja en adolescentes y jóvenes: una revisión. [Violence in Relationships in Adolescents and Young People: A Review.] Psicopatología Clínica Legal y Forense, 3, 23-39.

González, R., \& Santana, J. D. (2001). La violencia en parejas jóvenes. [Violence among Young Partners.] Psicothema, 13, 127-131.

Graña, J. L., \& Cuenca, M. L. (2014). Prevalence of Psychological and Physical Intimate Partner Aggression in Madrid (Spain): A Dyadic Analysis. Psicothema, 26, 343-348.

Hird, M. J. (2000). An Empirical Study of Adolescent Dating Aggression in the U.K. Journal of Adolescence, 23, 69-78. https://doi.org/10.1006/jado.1999.0292

Jackson, S. M., Cram, F., \& Seymour, F. W. (2000). Violence and Sexual Coercion in High School Students' Dating Relationships. Journal of Family Violence, 15, 23-36. https://doi.org/10.1023/A:1007545302987

Katz, J., Carino, A., \& Hilton, A. (2002). Perceived Verbal Conflict Behaviors Associated with Physical Aggression and Sexual Coercion in Dating Relationships: A Gender-Sensitive Analysis. Violence and Victims, 17, 93-109. https://doi.org/10.1891/vivi.17.1.93.33641

McNulty, J. K., \& Russell, V. M. (2010). When "Negative” Behaviors Are Positive: A Contextual Analysis of the Long-Term Effects of Problem Solving Behaviors on Changes in Relationship Satisfaction. Journal of Personality and Social Psychology, 98, 587-604. https://doi.org/10.1037/a0017479

Muñoz-Rivas, M., Andreu, J. M., Graña, J. L., O’Leary, D. K., \& González, M. P. (2007). Validación de la versión modificada de la Conflicts Tactics Scale (M-CTS) en población juvenil española. [Validation of the Modified Version of the Conflict Tactics Scale (M-CTS) in a Spanish Population of Youths.] Psicothema, 19, 693-698.

Murphy, C. M., \& Hoover, S. A. (2001). Measuring Emotional Abuse in Dating Relationships as a Multifactorial Construct. En K. D. O’Leary, \& R. D. Maiuro (Eds.), Psychological Abuse in Violent Relationships (pp. 29-46). New York: Springer.

Murphy, C. M., \& O’Leary, K. D. (1989). Psychological Aggression Predicts Physical Aggression in Early Marriage. Journal of Consulting and Clinical Psychology, 57, 579-582. https://doi.org/10.1037/0022-006X.57.5.579

O’Keefe, M. (1997). Predictors of Dating Violence among High School Students. Journal 
of Interpersonal Violence, 12, 546-568. https://doi.org/10.1177/088626097012004005

O'Leary, K. D. (1999). Developmental and Affective Issues in Assessing and Treating Partner Aggression. Clinical Psychology: Science and Practice, 6, 400-414. https://doi.org/10.1093/clipsy.6.4.400

O’Leary, K. D., \& Slep, A. M. (2003). A Dyadic Longitudinal Model of Adolescent Dating Aggression. Journal of Clinical Child and Adolescent Psychology, 32, 314-327. https://doi.org/10.1207/S15374424JCCP3203_01

Sackett, L. A., \& Saunders, D. G. (1999). The Impact of Different Forms of Psychological Abuse on Battered Women. Violence and Victims, 14, 105-177. https://doi.org/10.1891/0886-6708.14.1.105

Sebastián, J., Ortiz, B., \& Gil, M. (2010). La violencia en las relaciones de pareja de los jóvenes, ¿Hacia dónde caminamos? [Violence in Young Couples. What Is the Way Ahead?] Clínica Contemporánea, 1, 71-83. https://doi.org/10.5093/cc2010v1n2al

Shortt, J. W., Capaldi, D. M., Kim, H. K., \& Laurent, H. K. (2010). The Effects of Intimate Partner Violence on Relationship Satisfaction over Time for Young at-Risk Couples: The Moderating Role of Observed Negative and Positive Affect. Partner Abuse, 1, 131-152. https://doi.org/10.1891/1946-6560.1.2.131

Soler, E., Barreto, P., \& González, R. (2005). Cuestionario de respuesta emocional a la violencia doméstica y sexual. [Questionnaire of Emotional Response to Domestic and Sexual Violence.] Psicothema, 17, 267-274.

Stith, S. M., Green, N. M., Smith, D. B., \& Ward, D. B. (2008). Marital Satisfaction and Marital Discord as Risk Markers for Intimate Partner Violence: A Meta-Analytic Review. Journal of Family Violence, 23, 149-160. https://doi.org/10.1007/s10896-007-9137-4

Swart, L. A., Garth, M. S., \& Ricardo, I. (2002). Violence in Adolescents' Romantic Relationships: Findings from a Survey amongst School-Going Youth in a South African Community. Journal of Adolescence, 25, 385-395. https://doi.org/10.1006/jado.2002.0483

Vázquez, F., Torres, A., Otero, P., Blanco, V., \& López, M. (2010). Prevalencia y factores de riesgo de la violencia contra la mujer en estudiantes universitarias españolas. [Prevalence and Risk Factors of Violence against Women among Spanish Female University Students.] Psicothema, 22, 196-201.

White, J. W., Merrill, L. L., \& Koss, M. P. (2001). Prediction of Premilitary Courtship Violence in a Navy Recruit Sample. Violence and Victims, 16, 910-927.

https://doi.org/10.1177/088626001016009004 


\section{Appendix}

Questionnaire on Micro Male Conducts of Ferrer et al. (2008), adapted for bidirectionality behaviours.

The following is a list of behaviours that can occur in relationships. Check the box based on how many times each option has happened in your current relationship. If you currently do not have a partner, complete the questions according to your most recent relationship.

0-Never, 1-Seldom, 2-Sometimes and 3-Often.

1.1. You have frightened the partner through your tone of voice, glance or gestures

1.2. Your partner has frightened you through his/her tone of voice, glance or gestures

2.1. You have made important decisions without taking the opinion of your partner into account

2.2. Your partner has made important decisions without taking your opinion into account

3.1. You have changed decisions made by his/her partner

3.2. Your partner has changed decisions that you have made

4.1. You have not respected your partner's opinions and rights

4.2. Your partner has not respected your opinions and rights

5.1. You have not respected your partner's feelings

5.2. Your partner has not respected your feelings

6.1. You have got what you want from your partner due to fatigue, getting it due to his/her burnout

6.2. Your partner has got what he wanted from you due to fatigue

7.1. You control your partner's money or expenses

7.2. Your partner controls your money or expenses

8.1. You control your partner's schedules, meetings or activities

8.2. Your partner controls your schedules, meetings or activities

9.1. You complain to your partner because he/she goes out or relate to his/her family and friends

9.2. Your partner complains because you go out or relate to your family or friends

10.1. You tend to monopolize the use of common spaces or elements (sofa, TV remote, computer, car or motorcycle...)

10.2. Your partner tends to monopolize the use of common spaces or elements

11.1. (Answer only if you are a straight woman) Does your partner think that your main role in life is to be a mother?

11.2. (Answer only if you are a straight man) Do you think that the main role in your partner's life is to be a mother?

12.1. You discourage your partner or make it difficult for him/her to study or work

12.2. Your partner discourages you or makes it difficult for you to study or work

13.1. You cause insecurities or feelings of guilt in your partner by insinuating or manipulating emotions

13.2. Your partner causes you insecurities or feelings of guilt in your partner by insinuating or manipulating emotions

14.1. You get angry or make surly or aggressive comments unexpectedly and without your partner knowing the reason 


\section{Continued}

14.2. Your partner gets angry or makes surly or aggressive comments unexpectedly and without your knowing the reason

15.1. You have interrupted, not listened, not answering or you have manipulated the message

15.2. Your partner has interrupted you, has not listened you, has not answering to you or has manipulated the message

16.1. Do you think your partner is like a child that needs to be cared for or protected

16.2. Your partner treats you like a child that needs to be cared for or protected

17.1. You have read the messages or emails that they send to your partner without their permission, or you listen to telephone conversations without them knowing

17.2. Do you think your partner reads messages or emails without your permission

18.1. You don't express your own feelings, often you close emotionally

18.2. Your partner does not express their own feelings, often closes emotionally

19.1. You make excuses to justify yourself ("I didn't want to," "I didn't realize," "it was the fault of my obligations")

19.2. Your partner makes excuses to justify himself ("I didn't want to," "I didn't realize," "it was the fault of my obligations")

20.1. You cheat, lie or do not comply with partner agreements

20.2. Your partner cheats you, lies or does not comply with partner agreements

21.1. You disregard the responsibilities or domestic tasks

21.2. Your partner disregards domestic responsibilities or tasks

22.1. You question the fidelity of your partner

22.2. Your partner questions your fidelity

23.1. Your threats to leave the relationship or to have an affair with another person

23.2. Your partner threatens you to leave the relationship or to have an affair with another person

24.1. You make your partner feel sorry for you ("without you I don't know what to do", "if you're not there, something bad will happen to me").

24.2. Your partner makes you feel sorry for him/her

25.1. You downplay the duties or activities that your partner performs

25.2. Your partner downplays the duties or activities you do 